\title{
Effects of Solvent Type and Process Parameters on Electrospinnability of Zein through Orthogonal Experimental Design
}

\author{
Tuğba İNANÇ HORUZ* * Kadir Bülent BELİBAĞLI
}

\author{
Gaziantep University, Engineering Faculty, Food Engineering Department, 27310 Gaziantep, Turkey \\ crossref http://dx.doi.org/10.5755/j01.ms.24.1.17809
}

Received 22 March 2017; accepted 23 June 2017

\begin{abstract}
Electrospinning of zein from its solution with a non-toxic solvent is not easy. It certainly requires understanding the effects of critical parameters during electrospinning. In this paper, the first aim was to understand how the morphology and diameters of fibers produced from zein solutions were affected by solvent type used in solution and process parameters (flow-rate, voltage, and distance) by using Taguchi's orthogonal design. For this purpose, the optimum levels of factors were determined as follows: $12 \mathrm{kV}$ of voltage, $15 \mu \mathrm{L} / \mathrm{min}$ of flow rate, $10 \mathrm{~cm}$ of distance, and acetic acid as solvent in order to obtain the thinnest, bead-free nanofiber. Secondly, this combination was further validated by conducting a confirmatory experiment using five different zein concentrations to study the effect of concentration. The mean diameters of fibers with $24 \%$ zein concentrations were found as similar to the optimum conditions estimated, proving the applicability of Taguchi's method for electrospinning optimization.

Keywords: nanofiber, electrospinning, biomaterials, zein, Taguchi's orthogonal design.
\end{abstract}

\section{INTRODUCTION}

Electrospun nanofibers have many special characteristics, mainly because of their high surface to volume ratio. Moreover, they have low density, very high porosity and enhanced physico-mechanical properties $[1,2]$. Therefore, researchers have recently begun to look into various applications of electrospun fibers.

Basically, electrospun nanofibers are formed by spinning of a polymeric solution in an electric field into fibrils whose diameters are ranging from $10 \mathrm{~nm}$ to several hundred nanometers. For electrospinning to occur, the solution and process parameters have to meet a number of requirements. For example, the polymer solution must have an adequate concentration, viscosity, surface tension and conductivity. In addition to this, several process parameters such as voltage applied, flow rate of solution and distance between the tip of the needle and the collector must be in a suitable range of values. Controlling the elements above, uniform, bead-free and homogeneously distributed electrospun nanofibers with small diameter and desired morphology could be created. However, all of these parameters must be adjusted specifically depending on the types of polymer-solvent systems. Therefore, optimization of the conditions for each polymer-solvent system in order to get the best results becomes a challenging task. Electrospinning can be applied to both natural and synthetic polymers. However, natural polymers have attracted more attention of researchers in the field of electrospun nanofibers because of their better biocompatibility and non-toxicity. Recently, electrospinning of zein for various applications has drawn increasing attention. Zein, which is a class of prolamine protein found in corn, has been used particularly, in food and pharmaceutical industry as a coating material because

\footnotetext{
${ }^{*}$ Corresponding author. Tel.: +90-342-3172369; fax: +90-342-3172360.

E-mail address: tugbainanc@gantep.edu.tr (T. İ. Horuz)
}

of its hydrophobicity and good elasticity [3]. It also possesses the benefits of being renewable and biodegradable [4]. Zein nanofibers have the potential to be used for controlling release of active components, and as an active packaging material, etc. $[5,6]$. There are also various studies about electrospinning of zein, especially by incorporating of various functional compounds inside of them [7-9]. Moreover, composite zein fibers were produced by the blending of zein with several polymers in order to improve its electrospinnability $[10,11]$. Only a few studies reported the effects of processing factors or solvent types on the electrospun zein fibers $[12,13]$. However, only one comprehensive optimization study for electrospinning of zein has been reported, up to now [14]. This optimization study is different in the way of taking the effects of multiple variables acting simultaneously into account by using Taguchi's orthogonal design to produce nanofibers from zein.

In this paper one of the aims was to understand how the morphology and diameter of produced electrospun fibers from a solution of zein were affected by solvent type (glacial acetic acid, ethanol, and a mix of them) and process parameters (flow-rate, applied voltage, distance between the needle-tip and collector). Another was to optimize the electrospinning process parameters to get thinner zein fibers and narrower diameter size range indicating less jet instabilities. The final aim of the study was the further determination of the right concentration of zein to achieve thin, bead-free, smooth and homogeneously distributed fibers by conducting several experiments at the determined optimum conditions.

\section{EXPERIMENTAL}

\subsection{Materials}

Zein (Z 3625), glacial acetic acid (HAc), and ethanol $(\mathrm{EtOH})$ were purchased from Sigma Aldrich (St. Louis, Mo., U.S.A). 


\subsection{Experimental design}

Taguchi's orthogonal design can ensure a simple and systematic experimental design to optimize a set of electrospinning factors from a minimum number of carefully designed experiments. It employs orthogonal arrays for experimental design and signal-to-noise ratio, which is $\log$ function of desired output to determine the optimum settings of control factors and thus neglects the different causes of variations $[15,16]$.

Taguchi's orthogonal design was conducted by using Minitab 17 (Minitab Inc., USA) with two important aims in the present study. The first aim was to investigate the influences of three levels of four factors (voltage supplied, flow rate of solution, distance between collector and needle, and solvent type) on the diameter of electrospun fibers and dispersion of these sizes of diameters on the mat. Second was to optimize these parameters to get thinner fibers and narrower diameter size range indicating less jet instabilities. The experimental design with levels of factors are shown in Table 1. A combination of factors with different levels was designed according to the orthogonal array of L9 type shown in Table 2. A "smaller the better" characteristic formula has been used to determine the optimum combination of factors to minimize both the diameters of fibers and their variation in production of electrospun zein nanofibers as indicated in the equation below:

$\frac{S}{N}=-10 \log \left(\frac{1}{n} \sum_{i=1}^{n} y_{i}^{2}\right)$,

where $S / N$ is the signal-to-noise ratio, $\mathrm{n}$ is the number of observations, and $y$ is the diameter of zein nanofiber measured $[15,16]$.

Table 1. Selected factors and their levels used in Taguchi's design

\begin{tabular}{|l|c|c|c|}
\hline \multirow{2}{*}{\multicolumn{1}{|c|}{ Factor }} & \multicolumn{3}{c|}{ Level } \\
\cline { 2 - 4 } & 1 & 2 & 3 \\
\hline A, Voltage, $\mathrm{kV}$ & 12 & 16 & 20 \\
\hline B, Flow rate, $\mu \mathrm{L} / \mathrm{min}$ & 10 & 15 & 20 \\
\hline $\mathrm{C}$, Distance, $\mathrm{cm}$ & 10 & 12.5 & 15 \\
\hline $\mathrm{D}$, Solvent & $\mathrm{HAc}$ & $\mathrm{EtOH}$ & $\mathrm{HAc} / \mathrm{EtOH}$ \\
\hline
\end{tabular}

Table 2. L9 Orthogonal design for selected factors with their levels

\begin{tabular}{|c|c|c|c|c|}
\hline \multirow{2}{*}{ Run } & \multicolumn{4}{|c|}{ Factors } \\
\cline { 2 - 5 } & $\begin{array}{c}\text { Voltage, } \\
\mathrm{kV}\end{array}$ & $\begin{array}{c}\text { Flow rate, } \\
\mu \mathrm{L} / \mathrm{min}\end{array}$ & $\begin{array}{c}\text { Distance, } \\
\mathrm{cm}\end{array}$ & Solvent \\
\hline 1 & 12 & 10 & 10.0 & $\mathrm{HAc}$ \\
\hline 2 & 12 & 15 & 12.5 & $\mathrm{EtOH}$ \\
\hline 3 & 12 & 20 & 15.0 & $\mathrm{HAc} / \mathrm{EtOH}$ \\
\hline 4 & 16 & 10 & 12.5 & $\mathrm{HAc} / \mathrm{EtOH}$ \\
\hline 5 & 16 & 15 & 15.0 & $\mathrm{HAc}$ \\
\hline 6 & 16 & 20 & 10.0 & $\mathrm{EtOH}$ \\
\hline 7 & 20 & 10 & 15.0 & $\mathrm{EtOH}$ \\
\hline 8 & 20 & 15 & 10.0 & $\mathrm{HAc} / \mathrm{EtOH}$ \\
\hline 9 & 20 & 20 & 12.5 & $\mathrm{HAc}$ \\
\hline
\end{tabular}

\subsection{Preparation of solutions}

For optimization study, $25 \%$ zein solutions were prepared by using pure acetic acid (HAc), $80 \%$ (v/v) aqueous ethanol solution $(\mathrm{EtOH})$, and the mixture of acetic acid and $80 \%$ (v/v) aqueous ethanol solution, HAc/EtOH $(1: 1)$ as three different solvents. After that, five different concentrations $(16,20,24,28$, and $32 \mathrm{w} / \mathrm{w})$ of zein solutions were prepared by using the determined solvent according to the optimization results. The solutions were obtained after constant stirring using a magnetic stirrer at room temperature.

\subsection{Characterization of solutions}

Viscosities of the prepared polymer solutions were determined at $24^{\circ} \mathrm{C}$ by using Haake Rheostress RS1 (Karslruhe, Germany) equipped with a plate-plate sensor (dia $35 \mathrm{~mm}$, gap $1 \mathrm{~mm}$ ). The shear rate ranged from 0 to $200 \mathrm{~s}-1$ in $60 \mathrm{~s}$ during viscosity measurement.

Surface tension and electrical conductivity values of the solutions were determined by using a tensiometer (Krüss K6, Germany) and a conductivity meter (Orion 115A, Thermo, USA) at room temperature.

\subsection{Electrospinning}

Electrospinning process was carried out by using the Nanotel (NTEE 80-1, Turkey) electrospinning device consisting of a syringe pump, a high voltage power supply and a collector plate covered in non-stick aluminum foil for easy removal of mats. The solutions were placed in 5 $\mathrm{ml}$ syringes fixed horizontally on the syringe pump delivering the solution to the tip of a metal needle where the voltage was applied. Fibers were then collected on the aluminum foil. Production of nanofibers were firstly made according to the process conditions shown in Table 2. Secondly, nanofibers were produced from different concentrations of zein solutions at the further determined optimum conditions of parameters.

\subsection{Morphological characterization}

The morphology and diameters of the produced nanofibers were examined by using a scanning electron microscope (SEM) (JEOL, JSM-6390LV, Japan) with accelerating voltage of $20 \mathrm{kV}$. Fiber diameter analysis was carried out by randomly counting 50 fibers per experiment using a software (ImageJ, 1.48V). The mean diameter and standard deviation were calculated as the responses. Moreover, analysis of the dispersion of nanofibers diameter was made according to the method established by Malašauskienè et al. [17].

\subsection{Statistical analysis and optimization}

The diameter values of the nanofibers obtained were statistically analyzed by using the Minitab-17 program (Minitab Inc., USA) and optimum conditions were determined. For confirmation, one more experiment was conducted at the determined conditions.

\section{RESULTS AND DISCUSSION}

\subsection{Characteristics of zein solutions}

In the current study, the change of solvent type caused also the changes in conductivity, surface tension, and viscosity values as shown in Table 3 . It is well-known that the morphology of electrospun nanofibers depends on not 
only operating conditions, but also these solution characteristics [18]. The most critical parameter among them is surface tension since it determines the upper and lower limits of the electrospinning process if other parameters are kept constant. High surface tension is generally known to inhibit the electrospinning process, thus resulting in the formation of drops instead of spinning [19]. However, in this study surface tension values of the solutions were not so high that they mostly did not hinder the spinning process. Despite having the highest surface tension value $(30 \mathrm{mN} / \mathrm{m})$ as shown in Table 4 , smooth and homogenous nanofibers were produced via continuous spinning of HAc-based zein solution because of its moderate viscosity value. However, as shown in Fig. 1 beaded fibers were produced by spinning of EtOH/HAcbased zein solution because of the combined effect of low viscosity and high surface tension. It is important to be aware of that for a low-viscosity polymer solution, surface tension is the dominant factor and beaded fiber may form [20].

The viscosity values of the solutions in Table 3 were seen as higher in the presence of the HAc, probably due to increased aggregation of molecules at acidic $\mathrm{pH}$ levels $[21,22]$. Generally, increased viscosity causes increasing fiber diameter. However, thicker zein fibers (respectively 220, 207, and $308 \mathrm{~nm}$ ) were produced from the EtOHbased solution in Run-2, Run-6, and Run-7, in spite of its lower viscosity than others (Fig. 1 and Table 3). This observation might be attributed to the fact that $\mathrm{EtOH}$ is more volatile and thus evaporated faster. This results in a greater increase of the viscosity of a polymer solution at the tip of the needle during spinning, leading to formation of thicker fibers [18].

When HAc-based solution was used in Run-1, Run-5, and Run-9, the fibers with the larger diameters (respectively 106, 181, and $264 \mathrm{~nm}$ ) were produced compared to those of fibers produced from $\mathrm{HAc} / \mathrm{EtOH}-$ based solution. It is consisted with several studies showing that higher viscosity in the feed polymer solution gives rise to the formation of uniform fibers with larger diameters due to polymer chain entanglements, which makes jet stretching more difficult [22-24].

It is shown in Table 3 that the conductivity values of solutions significantly increased when EtOH used.

Table 3. Characteristics of prepared zein solutions

\begin{tabular}{|c|c|c|c|c|}
\hline Run & Solution & $\begin{array}{c}\text { Viscosity, } \\
\text { Pa.s }\end{array}$ & $\begin{array}{c}\text { Conductivity, } \\
\mu \mathrm{S} / \mathrm{cm}\end{array}$ & $\begin{array}{c}\text { Surface } \\
\text { tension, } \\
\mathrm{mN} / \mathrm{m}\end{array}$ \\
\hline $1,5,9$ & $\begin{array}{c}\text { Zein in } \\
\text { HAc }\end{array}$ & $0.730 \pm 0.015$ & $37.1 \pm 0.2$ & $30.0 \pm 0.0$ \\
\hline $2,6,7$ & $\begin{array}{c}\text { Zein in } \\
\text { EtOH }\end{array}$ & $0.173 \pm 0.002$ & $762.7 \pm 1.7$ & $27.7 \pm 0.2$ \\
\hline $3,4,8$ & $\begin{array}{c}\text { Zein in } \\
\text { HAc/EtOH }\end{array}$ & $0.259 \pm 0.005$ & $455.7 \pm 0.5$ & $29.8 \pm 0.5$ \\
\hline
\end{tabular}

This caused a significant decrease in the mean diameters of the electrospun fibers in Run-3, Run-4, and Run-8 (respectively 80, 136, and $127 \mathrm{~nm}$ ). This phenomenon can be explained by the fact that increasing of conductivity also increases the charge density on the surface of the drop in the needle, which gives rise to increases in elongation forces exerted on the polymer jet providing a smaller fiber [20]. However, when EtOH was used as a single solvent, the fibers with larger diameters were obtained, despite its very high conductivity value. This might be due to the fact that very high volatility of EtOH resulted in greater viscosity as mentioned above and might create a dominant effect over the conductivity effect.

\subsection{Morphologies of zein nanofibers}

At first glance to the SEM images in Fig. 1, it can be easily seen that zein nanofibers obtained in Run-1, Run-5, and Run-9, in which HAc was used as the solvent, showed bead-free, smooth, and homogeneously distributed morphology. This better morphology compared to the fiber morphologies produced from the EtOH-based solution was the result of that the spinning continuity of the HAc-based solution was much better than that of the EtOH-based solution. This might be because of the lower vapor pressure of HAc which would reduce the amount of solvent that was evaporating at the needle tip [12]. The mean diameters of these fibers range from 106 to $264 \mathrm{~nm}$ (Table 4). However, Selling et al. and Miri et al. produced nanofibers with larger diameters (above $400 \mathrm{~nm}$ ) from the zein solution in HAc, probably due to the combined effect of higher voltage (above $20 \mathrm{kv}$ ) and higher zein concentrations used in their study $[12,14]$.

The fibers with larger diameters, ranging from 207 to $308 \mathrm{~nm}$, were obtained by electrospinning of zein solution in $\mathrm{EtOH}$ compared to those in $\mathrm{HAc}$ or $\mathrm{HAc} / \mathrm{EtOH}$. The diameters of these fibers (Run-2, Run-6, and Run-7) were also distributed in a wide range of values with very high standard deviations (Table 4). Neo et al. also obtained the similar results in their study, in which $25 \%$ zein solution in $\mathrm{EtOH}$ was electrospun using similar process conditions [8]. These EtOH-based zein fibers are also different from others with their morphology. They have ribbon-like fiber morphology resulted from rapid skin formation and collapsing of fibers due to the high volatility of $\mathrm{EtOH}$ $[13,25]$. The high volatility of $\mathrm{EtOH}$ also caused clogging of the polymer at the tip of the needle, which is a general problem that occurs during electrospinning [26, 27]. This made the electrospinning process quite laborious and caused the formation of non-smooth irregular shaped fibers (Fig. 1).

The values of mean diameter and standard deviation of electrospun fibers remarkably decreased when $\mathrm{HAc} / \mathrm{EtOH}$ was used as a solvent (Table 3). However, a number of beads were observed along the electrospun fibers (Fig. 1), probably due to the combined effect of low viscosity and high surface tension. More beads were formed in the fiber structures obtained in Run-3 and Run- 8 compared to Run-4. This might be explained by the higher flow rate values used in these two runs. According to Pillay et al., high flow rate of polymer solution cause formation of beaded fibers, which is attributed to the larger droplet of the polymer solution at the end of the capillary. This results in incomplete drying because of non-evaporation of the solvent and low stretching of the solution in the flight between the needle and the collector [28]. 


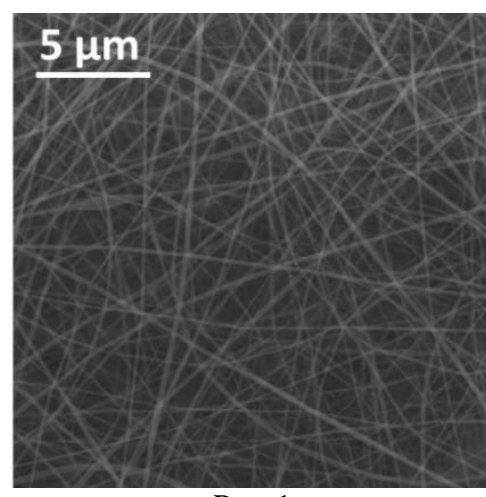

Run-1

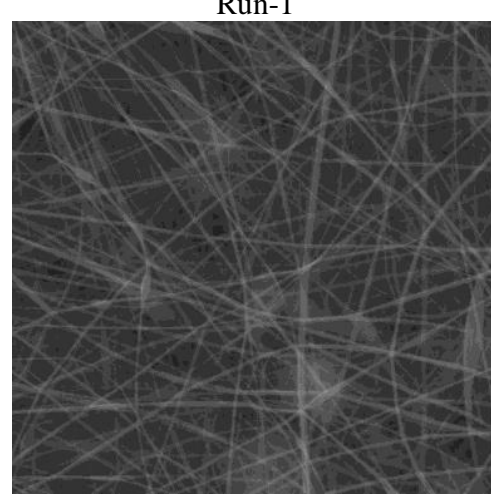

Run-4

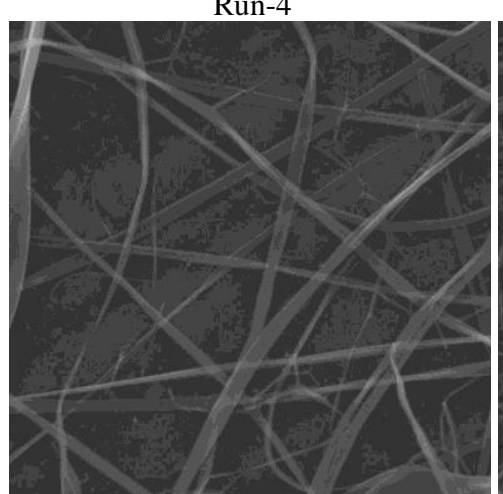

Run-7

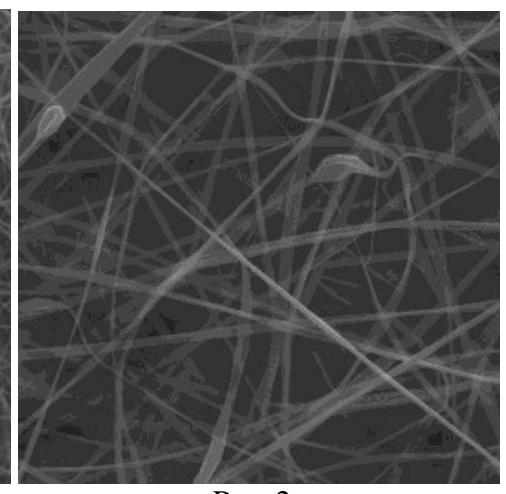

Run-2

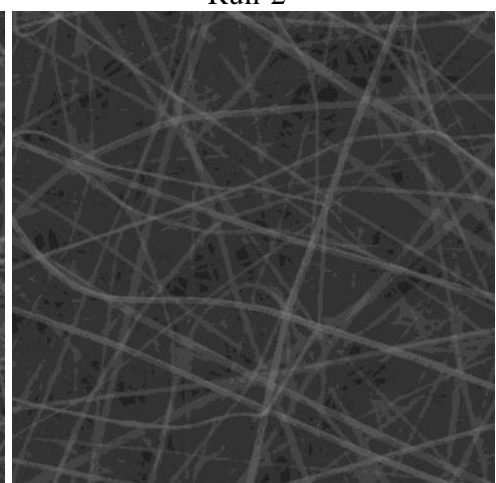

Run-5

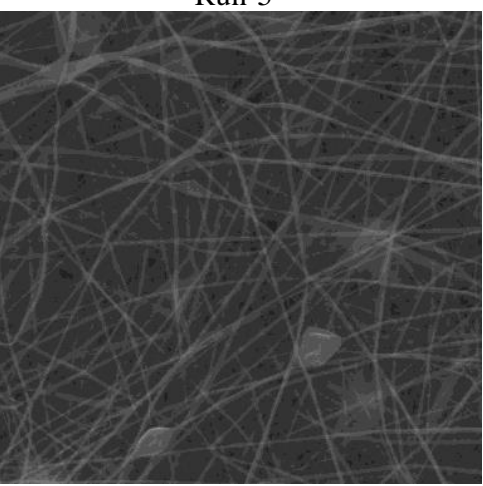

Run-8

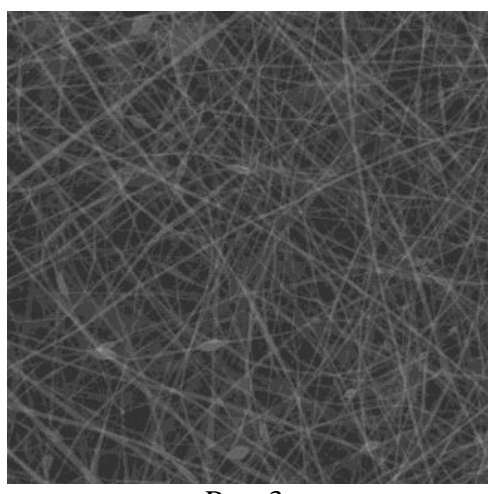

Run-3

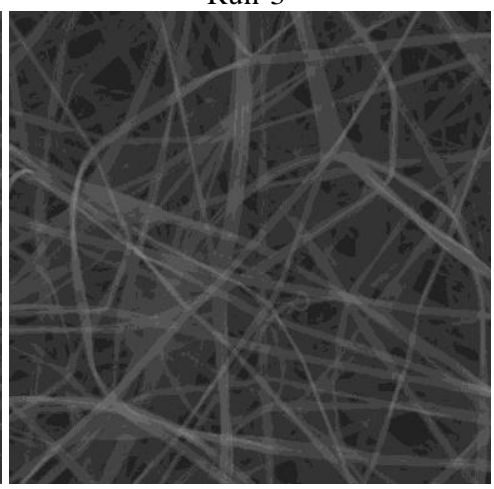

Run-6

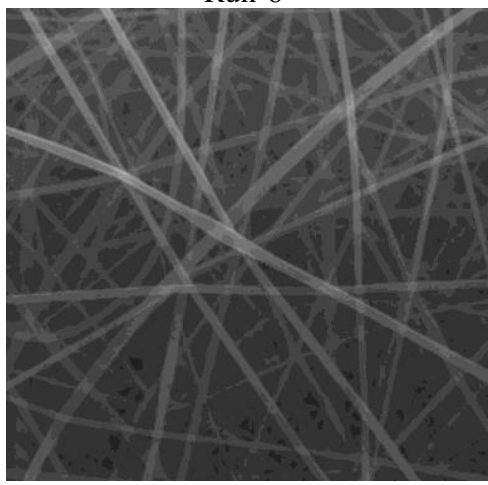

Run-9

Fig. 1. SEM images of electrospun zein nanofibers produced according to the experimental design shown in Table 2

Table 4. Experimental results of zein fiber diameters with their corresponding standard deviations and signal-to-noise $(\mathrm{S} / \mathrm{N})$ ratios based on "smaller the better"

\begin{tabular}{|c|c|c|c|}
\hline Run & Designation & $\begin{array}{c}\text { Mean fiber } \\
\text { diameter, } \mathrm{nm}\end{array}$ & S/N values \\
\hline 1 & A1B1C1D1 & $106 \pm 29$ & -40.51 \\
\hline 2 & A1B2C2D2 & $220 \pm 74$ & -46.84 \\
\hline 3 & A1B3C3D3 & $80 \pm 18$ & -38.06 \\
\hline 4 & A2B1C2D3 & $136 \pm 35$ & -42.67 \\
\hline 5 & A2B2C3D1 & $181 \pm 43$ & -45.15 \\
\hline 6 & A2B3C1D2 & $207 \pm 59$ & -46.32 \\
\hline 7 & A3B1C3D2 & $308 \pm 102$ & -49.77 \\
\hline 8 & A3B2C1D3 & $127 \pm 28$ & -42.08 \\
\hline 9 & A3B3C2D1 & $264 \pm 80$ & -48.43 \\
\hline
\end{tabular}

\subsection{Analyzing the results by Taguchi's method}

The Taguchi method, in which orthogonal arrays are used to organize the factors and the levels affecting the process, offers the opportunity to be able to evaluate all parameters together or independently with the minimum number of experiments [15]. Taguchi used signal-to-noise $(\mathrm{S} / \mathrm{N})$ ratio, which measures the deviation of quality characteristics from the desired values in order to assess the quality. In this study, $\mathrm{S} / \mathrm{N}$ ratio values calculated by rearranging the results by 'Minitab-17' statistical software according to "smaller the better" characteristic formula and were given in Table 4. As depicted in Table 4, Run-7, where EtOH-based solution was electrospun by using the highest level of voltage applied, yielded the highest mean diameter of zein nanofibers with the highest range of variation $(308 \pm 102 \mathrm{~nm})$ and the lowest value of $\mathrm{S} / \mathrm{N}$ ratio (-49.77). In contrast, the thinnest nanofibers $(80 \pm 18 \mathrm{~nm})$ with the highest value of S/N (-38.06) ratio value were obtained in Run-3, where HAc/EtOH-based solution was electrospun by using the lowest level of voltage applied.

In order to realize the effects of each factor and level on the response, the mean fiber diameter and $\mathrm{S} / \mathrm{N}$ ratio value for different levels of each parameter were calculated as shown in Table 5. According to range analysis in this table, the differences between maximum and minimum values of the three levels were calculated and the degree of 
importance of each factor on the fiber diameter was determined in a way that the factor with larger range had a more significant effect on the fiber diameter.

From these results, it is clearly understood that the type of solvent in the solution is the most influential factor on the diameter of electrospun zein fiber. They were higher when EtOH was used only solvent in the zein solution; on the other hand, thinner but beaded fibers were produced when it was combined with HAc. However, as depicted in Fig. 1, smooth, bead-free, and homogeneously distributed fibers could be obtained by using HAc as a single solvent, but the diameters of these fibers not less than that of fibers produced from $\mathrm{HAc} / \mathrm{EtOH}$-based solution.

The applied voltage was found as the second influential factor on the zein fiber diameter. The fiber diameters were smaller when the applied voltage was $12 \mathrm{kV}$ and they increased with increasing voltage. In literature, the effect of voltage on the fiber diameter is also crucial and still controversial. Several researchers suggested that high levels of voltage applied accelerates jet extending and causes a greater volume of polymer solution to be drawn from the needle, resulting in the formation of the fibers with larger diameter [29, 30]. On the other hand, several researchers suggested that a strong electrical charge provides with a greater stretch of the polymer solution leading to usually decrease the fiber diameter [31, 32]. In addition to this, Sill and Recum showed that with an increase in the applied voltage beyond a critical value, the fiber diameter decreases initially because of a higher degree of jet stretching and then increases after a definite point [33]. In another study, Yördem et al. indicated that the effect of applied voltage on fiber diameter may vary by type of polymer-solvent system and the distance between the collector and the tip of the needle [34].

It is inferred from Table 5, the flow rate and the distance between the collector and the tip have fewer effects on the fiber diameter compared to other factors. Generally, increasing the flow rate increases the fiber diameter because of more fluid ejection in a jet [35]. Although the distance between the collector and the tip is generally thought as the least important factor, its effect is almost the same as for increasing voltage $[2,23,36]$. In the current study, the effects of the flow rate and the distance showed both increasing and decreasing trends. The explanation for this observation is that the effects of these two parameters also vary with other parameters.

\subsection{Optimum combinations of factors and confirmation experiment}

Fig. 2 shows the mean effects of each factor on the mean diameter of fibers. According to Table 5 and Fig. 2, optimum levels of the factors were determined as the following conditions: $12 \mathrm{kV}$ of applied voltage, $15 \mu \mathrm{L} / \mathrm{min}$ of solution flow rate, $10 \mathrm{~cm}$ of distance between the needle tip to the collector, and $\mathrm{HAc} / \mathrm{EtOH}$ as solvent in order to obtain the thinnest nanofiber. However, it was decided to use HAc instead of $\mathrm{HAc} / \mathrm{EtOH}$ because of the bead formation on the fibers produced from $\mathrm{HAc} / \mathrm{EtOH}$-based solution and its poor spinning due to the high volatility of $\mathrm{EtOH}$.

Table 5. Response table for means of fiber diameters and $\mathrm{S} / \mathrm{N}$ values

\begin{tabular}{|c|c|c|c|c|c|c|c|c|}
\hline \multirow{2}{*}{ Level } & \multicolumn{4}{|c|}{ Means of fiber diameters, nm } & \multicolumn{4}{c|}{ Means of S/N values } \\
\cline { 2 - 9 } & $\mathrm{A}$ & $\mathrm{B}$ & $\mathrm{C}$ & $\mathrm{D}$ & $\mathrm{A}$ & $\mathrm{B}$ & $\mathrm{C}$ & $\mathrm{D}$ \\
\hline 1 & 135.3 & 183.3 & 146.7 & 183.7 & -41.81 & -44.32 & -42.97 & -44.70 \\
\hline 2 & 174.7 & 176.0 & 206.7 & 245.0 & -44.71 & -44.69 & -45.98 & -47.65 \\
\hline 3 & 233.0 & 183.7 & 189.7 & 114.3 & -46.76 & -44.27 & -44.33 & -40.94 \\
\hline Range & 97.7 & 7.7 & 60.0 & 130.7 & 4.95 & 0.42 & 3.02 & 6.71 \\
\hline Importance & 2 & 4 & 3 & 1 & 2 & 4 & 3 & 1 \\
\hline Best level & $12 \mathrm{kV}$ & $15 \mu \mathrm{L} / \mathrm{min}$ & $10 \mathrm{~cm}$ & $\mathrm{HAc} / \mathrm{EtOH}$ & \multicolumn{3}{c|}{} \\
\hline
\end{tabular}

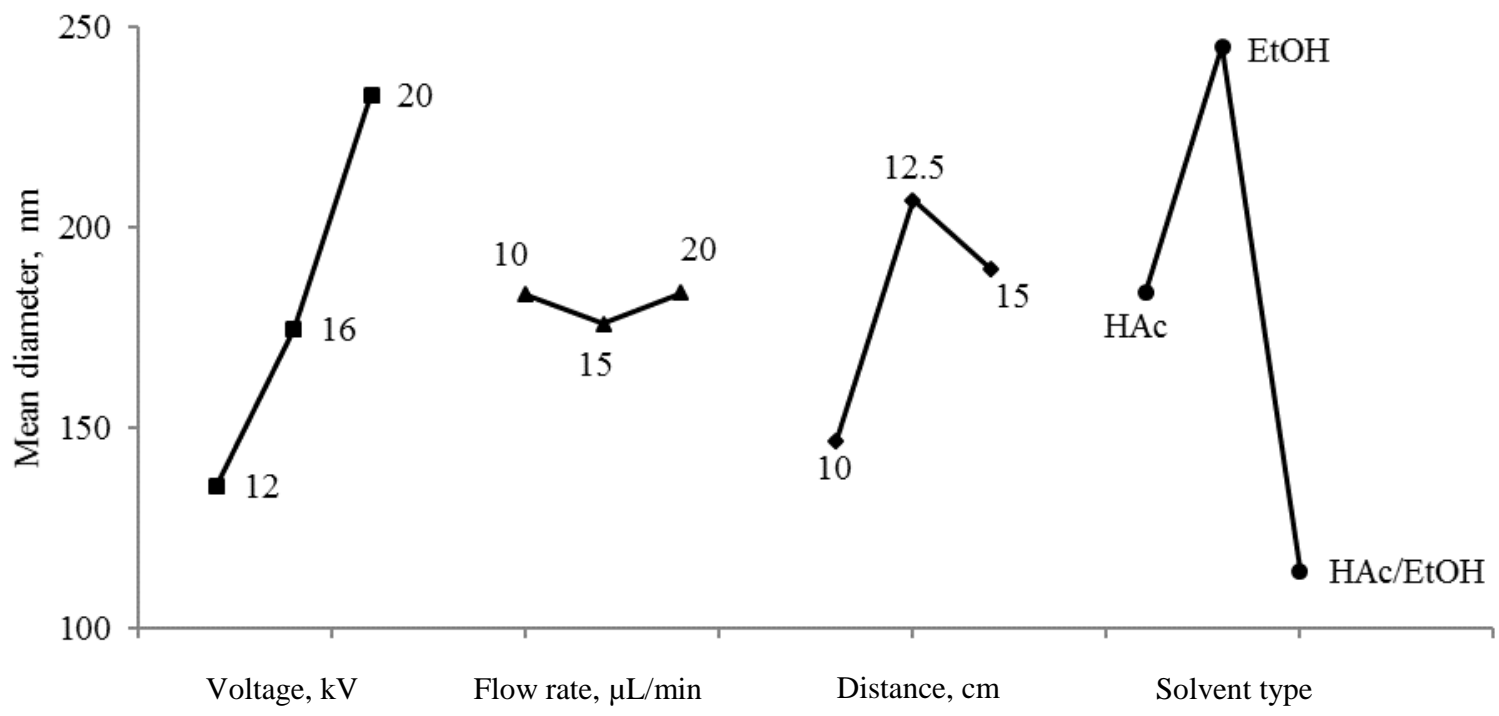

Fig. 2. Main effect plots of each parameter on means of nanofiber diameter 

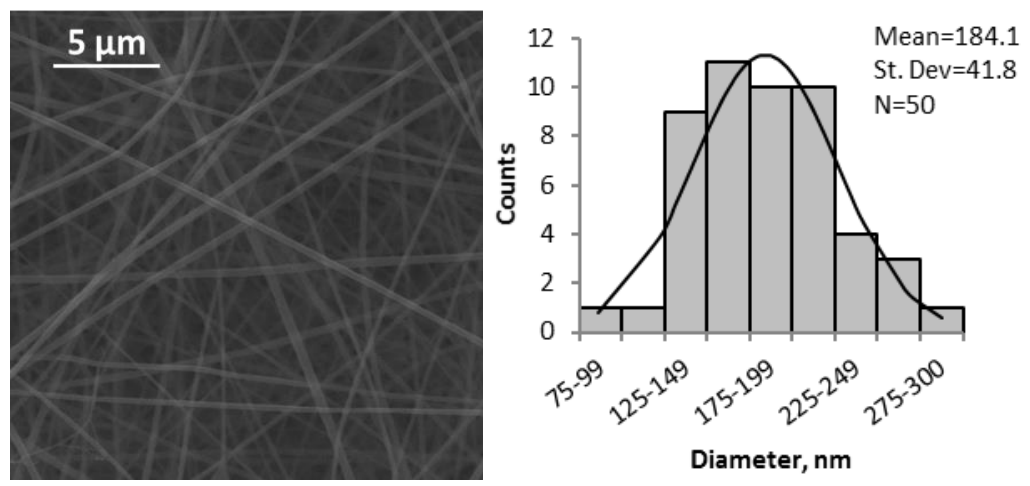

Fig. 3. SEM image and bar graph of diameter ranges of electrospun zein nanofibers obtained with the optimized conditions (12 kV; $15 \mu \mathrm{L} / \mathrm{min} ; 10 \mathrm{~cm} ; \mathrm{HAc})$

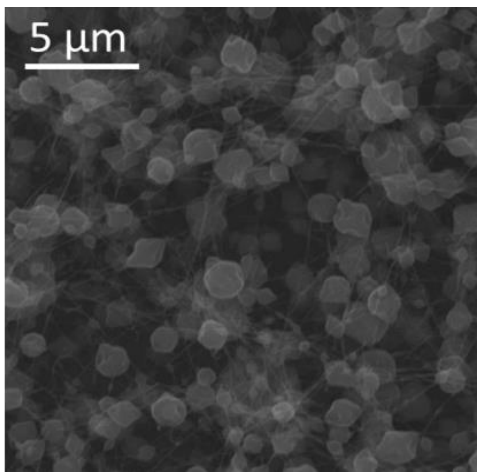

$16 \%$

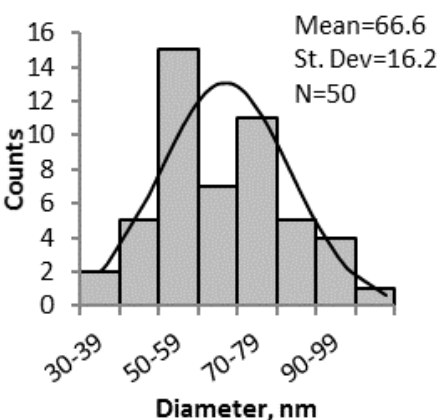

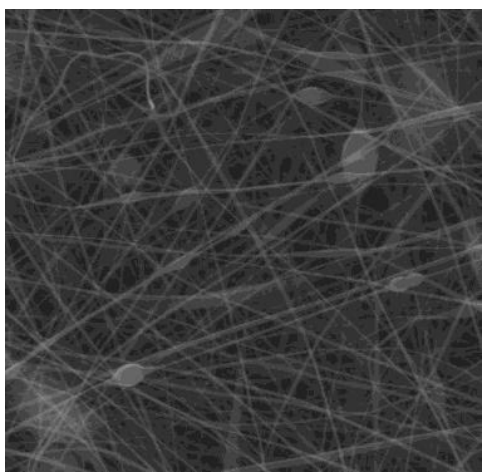

$20 \%$

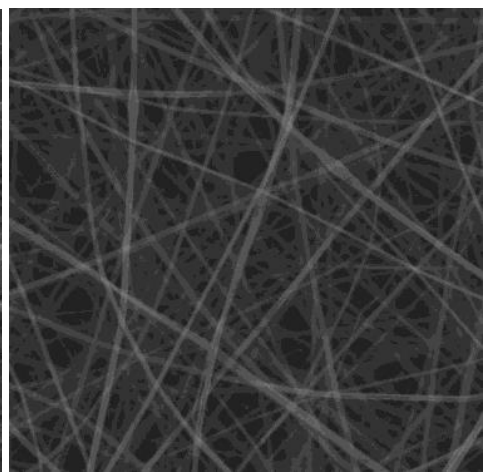

$24 \%$

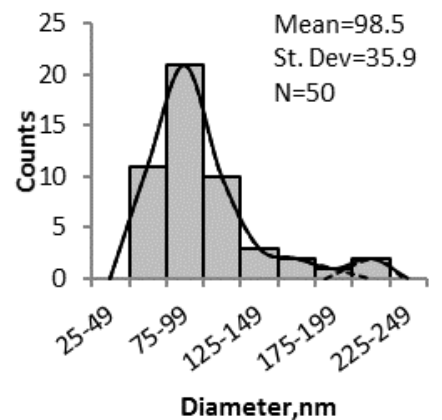

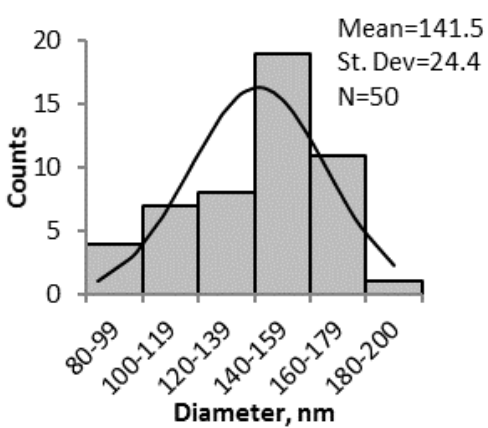
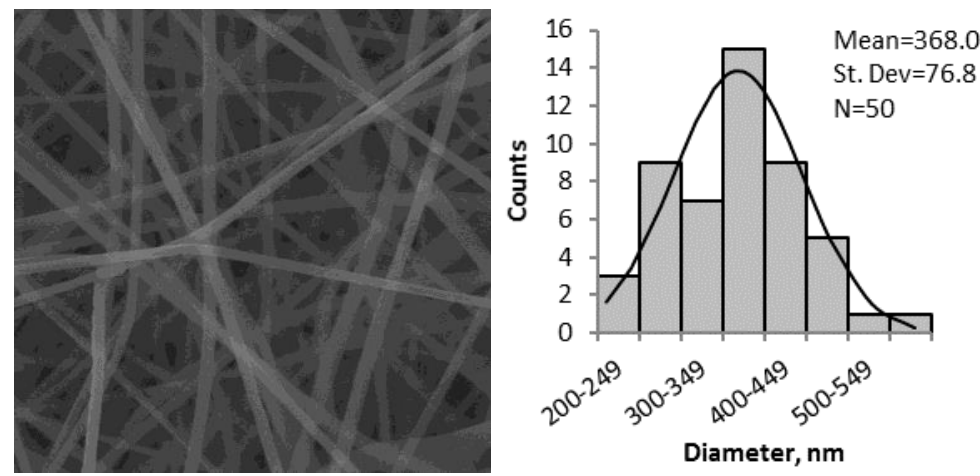

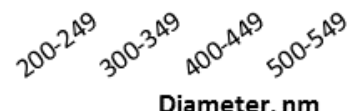

$28 \%$

Fig. 4. SEM images and bar graphs of diameter ranges of electrospun zein nanofibers obtained from different concentrations of zein solutions at the optimized conditions $(12 \mathrm{kV}, 15 \mu \mathrm{L} / \mathrm{min}, 10 \mathrm{~cm}, \mathrm{HAc})$

Fig. 3 shows the SEM images with diameter distribution of electrospun zein nanofibers obtained with the optimized conditions. According to the images and bar graphs, bead-free, smooth and homogenous zein nanofibers with small diameters were able to obtain.

\subsection{Effect of zein concentration}

The morphologies of the electrospun nanofibers at various concentrations of zein solution obtained by using the optimum conditions were illustrated in Fig. 4. Even though 
the most homogenous nanofibers with the smallest mean diameter (about $66 \mathrm{~nm}$ ) were obtained from the zein solution at $16 \%(\mathrm{w} / \mathrm{w})$, many beads were observed along these fibers probably due to the low viscosity resulting in spraying of the solution [23]. However, fewer beads were formed when the zein concentration increased to $20 \%$ (w/w), attributing to increase in the viscosity (Table 6).

Table 6. Characteristics of the zein solutions prepared with HAc at different concentrations

\begin{tabular}{|c|c|c|c|}
\hline $\begin{array}{c}\text { Zein \%, } \\
\text { w/w }\end{array}$ & $\begin{array}{c}\text { Viscosity, } \\
\text { Pa.s }\end{array}$ & $\begin{array}{c}\text { Conductivity, } \\
\mu \mathrm{S} / \mathrm{cm}\end{array}$ & $\begin{array}{c}\text { Surface } \\
\text { tension, } \mathrm{mN} / \mathrm{m}\end{array}$ \\
\hline 16 & $0.080 \pm 0.011$ & $22.6 \pm 0.2$ & $28.8 \pm 0.2$ \\
\hline 20 & $0.212 \pm 0.009$ & $28.5 \pm 0.6$ & $29.5 \pm 0.4$ \\
\hline 24 & $0.549 \pm 0.005$ & $36.4 \pm 1.2$ & $29.8 \pm 0.2$ \\
\hline 28 & $1.328 \pm 0.009$ & $38.9 \pm 0.2$ & $30.5 \pm 0.0$ \\
\hline 32 & $3.185 \pm 0.181$ & $39.6 \pm 0.0$ & $30.8 \pm 0.2$ \\
\hline
\end{tabular}

With further increase of concentration, no bead formation was observed along the electrospun nanofibers, but the mean diameter of the fibers increased to $141.5 \mathrm{~nm}$ because of the high viscosity [23]. When the zein concentration was $28 \%(\mathrm{w} / \mathrm{w})$, the mean diameter of the fibers markedly increased to $368 \mathrm{~nm}$. There was no fiber production from the zein solution at $32 \%(\mathrm{w} / \mathrm{w})$ because of hindering spinning due to very high viscosity combined with very high surface tension as shown in Table 6 . In the current study, both viscosity and surface tension values of the solutions increased with increasing zein concentration. It is probably attributed to that the increase in solution concentration could increase the cohesiveness among the water molecules at the liquid/air interface leading to the observed increase in surface tension of the solutions [37].

\section{CONCLUSIONS}

In this study, electrospinning of zein was optimized by employing an L9 orthogonal array along with $\mathrm{S} / \mathrm{N}$ ratios of Taguchi's method, in which effects of four factors (applied voltage, flow rate, distance between tip and collector, and solvent type) with three different levels on the morphologies of electrospun zein nanofibers were investigated. The solvent type was found as the most influential factor on the diameter of zein fibers. The smooth and bead-free nanofibers with smaller diameters were produced by electrospinning of the HAc-based zein solutions. The applied voltage was the second most influential factor on the fiber diameter. However, the flow rate and the distance between the collector and the tip were found to have fewer effects on the fiber diameter compared to other factors. The optimum combination of factors was determined as an applied voltage of $12 \mathrm{kV}$, a flow rate of $15 \mu \mathrm{L} / \mathrm{min}$, a distance of $10 \mathrm{~cm}$, and a solvent type of HAc. According to the electrospun fibers with different zein concentrations which were produced by using these optimum conditions, the thinnest fibers were produced at the zein concentrations of 16 and $20 \%$, but many bead structures were observed along these fibers. When the zein concentration of the solutions increased, the bead-free and smooth fibers could be produced, but the diameters of these fibers increased. However, the thinnest bead-free fibers were produced by electrospinning of the zein solution at the concentration of $24 \%$. In this study, it was also realized that the change of solvent type caused also the changes in conductivity, surface tension, and viscosity values, leading to changes in morphology and diameters of electrospun fibers.

Zein electrospun fibers have a strong potential to be used in food areas. Therefore, it is intended to use zein fibers in food packaging and encapsulation of food ingredients for further studies.

\section{Acknowledgements}

This research project was supported by Technological Research Council of Turkey (TUBITAK) (Project no: 1140731) which led to this paper. T. İnanç Horuz also acknowledges TUBITAK-BIDEB for the national $\mathrm{PhD}$ study scholarship (2211-C).

\section{REFERENCES}

1. Kim, J., Reeneker, D. Mechanical Properties of Composites Using Ultrafine Electrospun Fibers Polymer Composites 20 (1) 1999: pp. 124-131.

https://doi.org/10.1002/pc.10340

2. Frenot, A., Chronakis, I.S. Polymer Nanofibers Assembled by Electrospinning Current Opinion in Colloid \& Interface Science 8(1) 2003: pp. 64-75. https://doi.org/10.1016/S1359-0294(03)00004-9

3. Lawton, J.W. Zein: a History of Processing and Use Cereal Chemistry 79 (1) 2002: pp. 1-18. https://doi.org/10.1094/CCHEM.2002.79.1.1

4. Shukla, R., Cheryan, M. Zein: the Industrial Protein from Corn Industrial Crops and Products 13 2001: pp. $171-192$. https://doi.org/10.1016/S0926-6690(00)00064-9

5. Zhong, Q., Jin, M., Davidson, P.M., Zivanovic, S. Sustained Release of Lysozyme from Zein Microcapsules Produced by a Supercritical Anti-solvent Process Food Chemistry 115 (2) 2009: pp. 697-700. https://doi.org/10.1016/j.foodchem.2008.12.063

6. Alkan, D., Aydemir, L.Y., Arcan, I., Yavuzdurmaz, H., Atabay, H.I., Ceylan, C., Yemenicioğlu, A. Development of Flexible Antimicrobial Packaging Materials against Campylobacter jejuni by Incorporation of Gallic Acid into Zein-Based Films Journal of Agricultural and Food Chemistry 59 (20) 2011: pp. 11003-11010. https://doi.org/10.1021/jf202584b

7. Fernandez, A., Torres-Giner, S., Lagaron, J.M. Novel Route to Stabilization of Bioactive Antioxidants by Encapsulation in Electrospun Fibers of Zein Prolamine Food Hydrocolloids 23 (5) 2009: pp. 1427-1432. https://doi.org/10.1016/j.foodhyd.2008.10.011

8. Neo, Y.P., Ray, S., Jin, J., Gizdavic-Nikolaidis, M., Nieuwoudt, M.K., Liu, D., Quek, S.Y. Encapsulation of Food Grade Antioxidant in Natural Biopolymer by Electrospinning Technique: a Physicochemical Study Based on Zein-Gallic Acid System Food Chemistry $136(2)$ 2013: pp. $1013-1021$. https://doi.org/10.1016/j.foodchem.2012.09.010

9. Moomand, K., Lim, L.T. Oxidative Stability of Encapsulated Fish Oil in Electrospun Zein Fibres Food Research International 62 2014: pp. 523-532. https://doi.org/10.1016/j.foodres.2014.03.054

10. Torres-Giner, S., Ocio, M., Lagaron, J.M. Novel Antimicrobial Ultrathin Structures of Zein/Chitosan Blends obtained by Electrospinning Carbohydrate Polymers 77 (2) 2009: pp. $261-266$. 
https://doi.org/10.1016/j.carbpol.2008.12.035

11. Kayaci, F., Uyar, T. Electrospun Zein Nanofibers incorporating Cyclodextrins Carbohydrate Polymers 90 (1) 2012: pp. $558-568$. https://doi.org/10.1016/j.carbpol.2012.05.078

12. Selling, G.W., Biswas, A., Patel, A., Walls, D.J., Dunlap, C., Wei, Y. Impact of Solvent on Electrospinning of Zein and Analysis of Resulting Fibers Macromolecular Chemistry and Physics 208 2007: pp. $1002-1010$. https://doi.org/10.1002/macp.200700056

13. Torres-Giner, S., Gimenez, E., Lagaron, J.M. Characterization of the Morphology and Thermal properties of Zein Prolamine Nanostructures Obtained by Electrospinning Food Hydrocolloids 22 (4) 2008: pp. $601-614$. https://doi.org/10.1016/j.foodhyd.2007.02.005

14. Miri, M.A., Movaffagh, J., Najafi, M.B.H., Najafi, M.N,. Ghorani, B., Koocheki, A. Optimization of Elecrospinning Process of Zein Using Central Composite Design Fibers and Polymers 17 (5) 2016: pp. $769-777$. https://doi.org/10.1007/s12221-016-6064-0

15. Ross, P.J. Taguchi Techniques for Quality Engineering: Loss Function, Orthogonal Experiments, Parameter and Tolerance Design. McGraw-Hill, New York, 1996.

16. Albetran, H., Dong, Y., Low, I.M. Characterization and Optimization of Electrospun TiO2/PVP Nanofibers Using Taguchi Design of Experiment Method Journal of Asian Ceramic Society 3 (3) 2015: pp. 292-300. https://doi.org/10.1016/j.jascer.2015.05.001

17. Malašauskienè, J., Milašius, R., Kuchanauskaitė, E. Possibilities for the Estimation of Electrospun Nanofibre Diameter Distribution by Normal (Gaussian) Distribution Fibres \& Textiles in Eastern Europe 24 (2) 2016: pp. $23-28$. https://doi.org/10.5604/12303666.1191423

18. Fong, H., Chun, I., Reneker, D.H. Beaded Nanofibers Formed during Electrospinning Polymers 40 (16) 1999: pp. $4585-4592$. https://doi.org/10.1016/S0032-3861(99)00068-3

19. Hohman, M.M., Shin, M., Rutledge, G., Brenner, M.P. Electrospinning and Electrically Forced jets. II. Applications Physics of Fluids 13 (8) 2001: pp. 2221 - 2235. https://doi.org/10.1063/1.1384013

20. Li, Z., Wang, C. Effects of Working Parameters on Electrospinning: One-Dimensional Nanostructures. Springer, Berlin, 2013.

https://doi.org/10.1007/978-3-642-36427-3

21. Davanço, T., Tanada-Palmu, P., Grosso, C. Filmes Compostos de Gelatina, Triacetina, Acido Esteárico ou Capróico: Efeito do $\mathrm{pH}$ e da Adição de Surfactantes Sobre a Funcionalidade dos Filmes Revista Ciência e Tecnologia de Alimentos 27 2007: pp. 408-416. https://doi.org/10.1590/S0101-20612007000200034

22. Salles, T.H.C., Lombello, C.B., d'Avila, M.A. Electrospinning of Gelatin/Poly (vinyl pyrrolidone) Blends from Water/Acetic Acid Solutions Material Research 18 (3) 2015: pp. 509-518.

http://dx.doi.org/10.1590/1516-1439.310114

23. Ramakrishna, S., Fujihara, K., Teo, W.E., Lim, T.C., Ma, Z. An Introduction to Electrospinning and Nanofibers. World Scientific, Singapore, 2005. https://doi.org/10.1142/5894

24. Erencia, M., Cano, F., Tornero, J.A., Fernandes, M.M., Tzanov, T., Macanas, J., Carillo, F. Electrospinning of Gelatin Fibers Using Solutions with Low Acetic Acid Concentration: Effect of Solvent Composition on both
Diameter of Electrospun Fibers and Cytotoxicity Journal of Applied Polymer Science $132(25)$ 2015: pp. $42115(1-11)$. https://doi.org/10.1002/app.42115

25. Miyoshi, T., Toyohara, K., Minematsu, H. Preparation of Ultrafine Fibrous Zein Membranes via Electrospinning Polymer International 54 2005: pp. 1187-1190. https://doi.org/10.1002/pi.1829

26. Kanjanapongkul, K., Wongsasulak, S., Yoovidhya, T. Investigation and Prevention of Clogging during Electrospinning of Zein Solution Journal of Applid Polymer Science 118 (3) 2010: pp. 1821-1829. https://doi.org/10.1002/app.32499

27. Augustine, R., Kalarikkal, N., Thomas, S. Clogging-Free Electrospinning of Polycaprolactone Using Acetic Acid/Acetone Mixture Polymer-Plastics Technology and Engineering 55 (5) 2015: pp. 518-529. http://doi.org/10.1080/03602559.2015.1036451

28. Pillay, V., Dott, C., Choonara, Y.E., Tyagi, C., Tomar, L., Kumar, P., du Toit, L.C., Ndesendo, V.M.K. A Review of the Effect of Processing Variables on the Fabrication of Electrospun Nanofibers for Drug Delivery Applications Journal of Nanomaterials 2013 2013: pp. 1-22. http://doi.org/10.1155/2013/789289

29. Demir, M.M, Yilgor, I., Yilgor, E., $\quad$ Erman, B. Electrospinning of Polyurethanefibers Polymers 43 (11) 2002: pp. 3303-3309. https://doi.org/10.1016/S0032-3861(02)00136-2

30. Zhang, C., Yuan, X., Wu, L., Han, Y., Sheng, J. Study on Morphology of Electrospun Poly (vinyl alcohol) Mats European Polymer Journal 41 (3) 2005: pp. 423-432. https://doi.org/10.1016/j.eurpolymj.2004.10.027

31. Yuan, X., Zhang, Y., Dong, C., Sheng, J. Morphology of Ultrafine Polysulfone Fibers Prepared by Electrospinning Polymer International 53 (11) 2004: pp. 1704-1710. https://doi.org/10.1002/pi.1538

32. Bhardwaj, N., Kundu, S.C. Electrospinning: A Fascinating Fiber Fabrication Technique Biotechnology Advances 28 (3) 2010: pp. 325-347. https://doi.org/10.1016/j.biotechadv.2010.01.004

33. Sill, T.J., von Recum, H.A. Electrospinning: Applications in Drug Delivery and Tissue Engineering Biomaterials 29 (13) 2008: pp. 1989-2006.

https://doi.org/10.1016/j.biomaterials.2008.01.011

34. Yördem, O.S., Papila, M., Menceloğlu, Y.Z. Effects of Electrospinning Parameters on Polyacrylonitrile Nanofiber Diameter: An Investigation by Response Surface Methodology Materials \& Design 29 (1) 2008: pp. $34-44$. https://doi.org/10.1016/j.matdes.2006.12.013

35. Zuo, W., Zhu, M., Yang, W., Yu, H., Chen, Y., Zhang, Y. Experimental Study on Relationship between Jet Instability and Formation of Beaded Fibers during Electrospinning Polymer Engineering \& Science 45 (5) 2005: pp. $704-709$. https://doi.org/10.1002/pen.20304

36. Homayoni, H.-S.-A., Ravandi, H., Valizadeh, M. Electrospinning of Chitosan Nanofibers: Processing Optimization Carbohydrate Polymers 77 (3) 2009: pp. 656-661. https://doi.org/10.1016/j.carbpol.2009.02.008

37. Choktaweesap, N., Arayanarakul, K., Aht-Ong, D., Meechaisue, C., Supaphol, P. Electrospun Gelatin Fibers: Effect of Solvent System on Morphology and Fiber Diameters Polymer Journal 39 2007: pp. 622-631. https://doi.org/10.1295/polymj.PJ2006190 